\title{
First Italian birth after cryopreserved ovarian tissue transplantation in a patient affected by non-Hodgkin's lymphoma
}

\author{
Raffaella Fabbri ${ }^{\ddagger}{ }^{1}$, Maria Macciocca ${ }^{\ddagger}{ }^{1}$, Rossella Vicenti*,1, Roberto Paradisi ${ }^{1}$, Stefania \\ Rossi $^{2}$, Elena Sabattini ${ }^{3}$, Anna Gazzola ${ }^{3}$ \& Renato Seracchioli ${ }^{1}$ \\ ${ }^{1}$ Gynecology \& Physiopathology of Human Reproduction Unit, Department of Medical \& Surgical Sciences, University of Bologna, \\ S Orsola-Malpighi Hospital of Bologna, Italy \\ ${ }^{2}$ Department of Women, Child and Urological Diseases, Gynecology \& Physiopathology of Human Reproduction Unit, S \\ Orsola-Malpighi Hospital of Bologna, Italy \\ ${ }^{3}$ Unit of Hemolymphopathology, Department of Hematology \& Oncology, S Orsola-Malpighi University Hospital of Bologna, Italy \\ *Author for correspondence: rossella.vicenti@unibo.it \\ ¥The authors consider that the first two authors should be regarded as joint first authors
}

\section{Practice points}

- Ovarian tissue cryopreservation and transplantation is a valid strategy for preserving endocrine and reproductive functions in patients at high risk of premature ovarian failure due to anticancer treatments.

- To improve the safety of transplantation, the ovarian samples have to be analyzed to assess neoplastic contamination using molecular and histological analyses prior to graft.

- At disease remission, cryopreserved ovarian tissue may be transplanted into the patient, allowing the recovery of ovarian function and spontaneous pregnancy.

- The ovarian cortical strips may be grafted onto orthotopic sites, such as the atrophic ovary or pelvic peritoneum, close to infundibulopelvic ligaments or ovarian fossa, allowing the recovery of ovarian function and spontaneous pregnancy, or in heterotopic sites, such as the subcutaneous space of the forearm or abdominal wall, allowing recovery of endocrine function.

Thiscase report describes the first Italian live birth obtained by cryopreserved ovarian tissue transplantation in a woman affected by non-Hodgkin's lymphoma. Before anticancer treatments, several fertility preservation options were proposed. At 29 years the patient underwent laparoscopy for ovarian tissue cryopreservation. After treatments she experienced premature ovarian failure (POF) and asked for cryopreserved ovarian tissue transplantation. Before transplantation, ovarian samples were analyzed to assess neoplastic contamination and tissue quality. Two subsequent ovarian tissue transplantations were performed 4 and 7 years after cryopreservation. The follicle-stimulating hormone and luteinizing hormone reduction, estradiol increase and first menstrual cycle appeared 2 months after the second transplantation. The woman conceived spontaneously 5 months after the second transplantation. After 39 weeks of uneventful gestation, a healthy male baby was born. Ovarian tissue cryopreservation, thawing and transplantation successfully restored ovarian function and fertility after tissue storage.

First draft submitted: 11 October 2018; Accepted for publication: 12 October 2018; Published online: 4 December 2018

Keywords: cryopreservation • fertility • non-Hodgkin's lymphoma

Recent advances in cancer diagnosis and the use of new chemo/radiotherapy protocols have significantly increased survival rates for children and adults with cancer. However, these treatments are gonadotoxic and can severely compromise or totally destroy the reproductive potential of women by inducing premature ovarian failure (POF) [1]. The potential iatrogenic loss of fertility has a profound impact on young women and may be more stressful than the cancer diagnosis itself [2].

Ovarian tissue cryopreservation is a valid strategy for preserving endocrine and reproductive function in patients at high risk of POF. At remission, the cryopreserved ovarian tissue can be replanted in the patient, allowing the recovery 
of ovarian function and spontaneous pregnancy. The efficiency of cryopreserved ovarian tissue transplantation has been established in terms of ovarian function recovery (95\% of cases), number of live births exceeding 130 and induction of puberty [1].

Here we describe the first live birth obtained in Italy after cryopreserved ovarian tissue transplantation in a woman who received sterilizing cancer treatment for non-Hodgkin's lymphoma.

\section{Case report}

In June 2012, a 29-year-old woman (EC) was admitted to investigation due to the persistence of febrile episodes, irritating cough and pain in the left hemithorax. A bulky mediastinal mass was shown by chest $\mathrm{x}$-ray and a diagnosis of primary mediastinal large B-cell lymphoma (PMLBCL; Stage III A-score AAIPI high) was rendered. Both bone marrow biopsy and peripheral blood flow cytometry were negative for neoplastic involvement.

Several methods for fertility preservation such as in vitro fertilization (IVF), cryopreservation of ovarian tissue, embryo and oocyte and GnRH agonist cotreatment were discussed and the patient decided to proceed with ovarian tissue cryopreservation before cancer treatments. About $40 \%$ of the left and right ovaries was retrieved by laparoscopy and the ovarian tissue was cryopreserved according to Fabbri et al. [3].

A few days later, the patient started chemotherapy: four cycles of R-CHOP (rituximab, doxorubicin, cyclophosphamide, vincristine, prednisone), two cycles according to the MAD scheme (mitoxantrone, citarabine, dexamethasone) and a high-dose cycle of BEAM (carmustine, etoposide, citarabine, melphalan). In December 2012, the woman underwent reinfusion of autologous stem cells. Enantone was administered during all treatments. Due to the persistence of mediastinal hypercaptation, showed by positron emission tomography and computed axial tomography, the patient underwent mediastinal radiotherapy (2-44 Gy) reaching a complete remission. After treatment, a POF was revealed, confirmed by no menstrual cycle, menopausal levels of FSH, LH and estradiol $\left(\mathrm{E}_{2}\right)$ hormones and hot flushes onset. To counteract these symptoms, hormone-replacement therapy was administered to the patient since February 2014.

In the following years, the patient remained in complete remission and requested cryopreserved ovarian tissue transplantation in September 2015. Since hematologists indicated no contraindication to ovarian tissue transplantation, an assessment of the presence of malignant cells in the cryopreserved ovarian tissue, a gynecological evaluation (pelvic ultrasound and sonohysterography) and assessment of the seminal fluid of the husband were done.

Histological analysis and immunohistochemical investigation on fixed and paraffinized ovarian tissues revealed no evidence of pathologic lymphoid infiltration, and showed good preservation of the follicular and stromal component. The follicular density was 8 follicles $/ \mathrm{mm}^{2}$.

Molecular analysis was performed on both cryopreserved and formalin-fixed paraffin embedded (FFPE) ovarian tissue (right and left) and repeated twice, in order to determine rearrangement of genes coding for immunoglobulins heavy (IGH; FR1-FR2-FR3 regions) and light chains (IGK), since no other patient-specific markers were available. PCR assay was performed according to EUROCLONALITY protocols [4] and evaluated by GeneScanning analysis to determine clonal character. DNA was tested by control gene PCR (100-400 bp amplicons) in order to verify its integrity. DNA extracted from fixed and paraffinized tissue was unsuitable while analysis on cryopreserved-tissue DNA lead to an amplification of the FR3-IGH region: a polyclonal pattern was detected.

In January 2016 the woman discontinued hormone replacement therapy and in September 2016 gynecological ultrasound showed thin endometrial lining ( $2 \mathrm{~mm}$ of thickness), small ovaries with homogeneous structure (right $0.25 \mathrm{cc}$, left $0.8 \mathrm{cc}$ ), bilateral tubal patency and a FSH of $150 \mathrm{mIU} / \mathrm{ml}, \mathrm{LH} 59 \mathrm{mIU} / \mathrm{ml}$ and $\mathrm{E}_{2} 39 \mathrm{pg} / \mathrm{ml}$ hormone profile. The husband's spermiogram showed a normozoospermic seminal fluid.

In November 2016, the patient underwent laparoscopy for orthotopic ovarian tissue transplantation. On the day of surgery, four samples of tissue were thawed, according to a slightly modified thawing protocol [3] and rapidly transferred to the operating room in phosphate-buffered saline (PBS) medium supplemented with $10 \%$ human serum (HS; provided by the Transfusion Center of Sant'Orsola-Malpighi Hospital, Bologna, Italy) at $4^{\circ} \mathrm{C}$. The ovarian surface was decorticated and two slices were placed on the left ovary and one on the right ovary. The ovaries were then covered with Tabotamp ${ }^{\circledR}$ (Ethicon Inc., NJ, USA) and Evicel ${ }^{\circledR}$ (Ethicon Inc.; Figure 1A \& B). The last strip was placed in a peritoneal pocket created near the right tube (Figure 1C). During laparoscopy, some biopsies of the remnant ovaries were taken and their histological examination confirmed the total absence of follicles with an extensive fibrosis. After transplantation the woman was monitored monthly with ultrasound and blood tests. In March 2017 she reported the disappearance of hot flushes, the presence of cervical mucus and FSH 


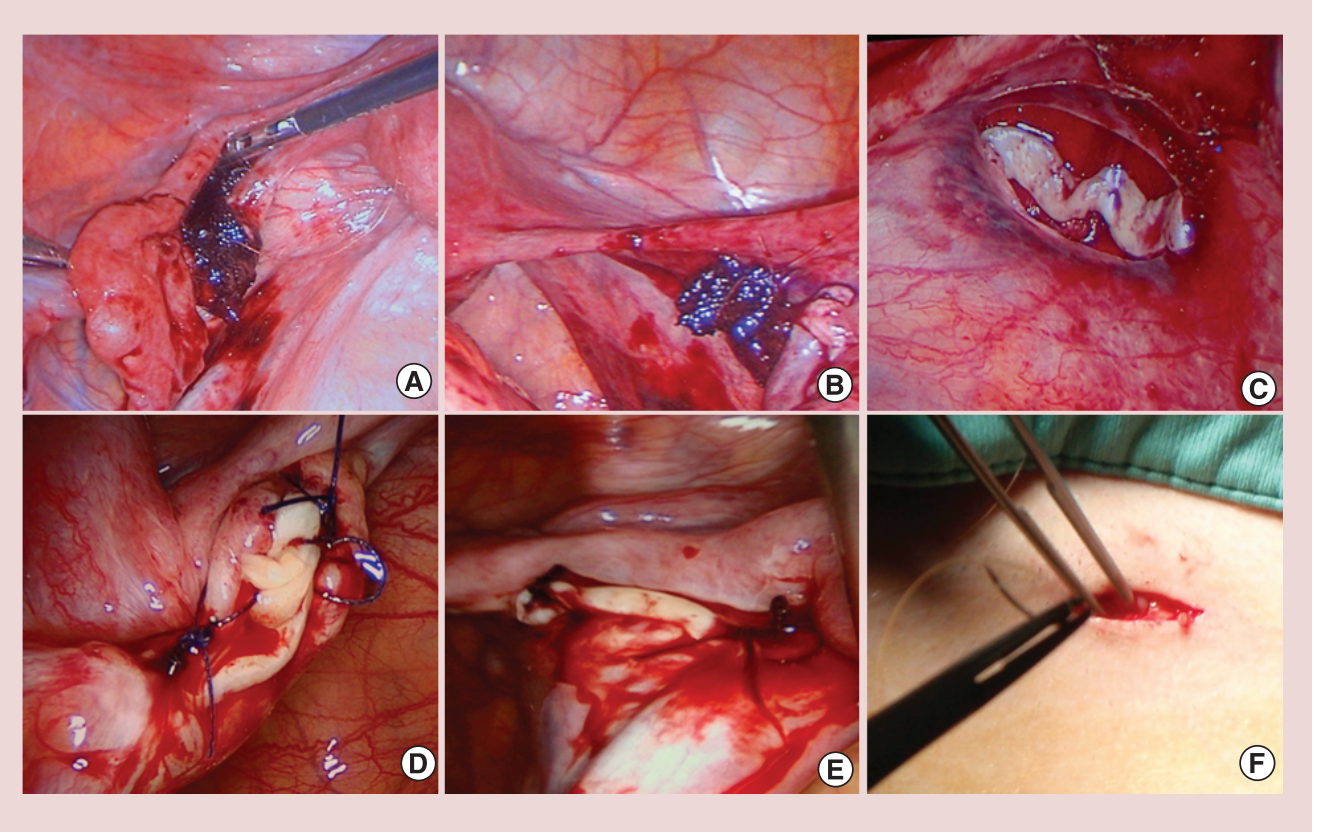

Figure 1. Ovarian tissue transplantations. First (A-C) and second (D-F) ovarian tissue transplantation. Left (A) and right (B) ovary transplanted with two and one slices, respectively, and covered with Tabotamp ${ }^{\circledR}$ (Ethicon Inc., NJ, USA) and Evicel ${ }^{\circledR}$ (Ethicon Inc.). (C) Strip placed in a peritoneal pocket. Cortical strips sutured into the left (D) and right ovary (E) closed with same sutures. (F) Heterotopic transplantation of ovarian tissue into a pocket created in a suprapubic area above the fascia.

was $61 \mathrm{mIU} / \mathrm{ml}, \mathrm{LH} 44 \mathrm{mIU} / \mathrm{ml}$ and $\mathrm{E}_{2} 82 \mathrm{pg} / \mathrm{ml}$. In the following months the FSH, LH and $\mathrm{E}_{2}$ returned to pretransplantation levels.

In June 2017, a second transplantation in orthotopic and heterotopic sites was performed. Before transplantation the ultrasound evaluation showed thin endometrial lining ( $2 \mathrm{~mm}$ of thickness), small ovaries with a homogeneous structure (right $0.8 \mathrm{cc}$ and left $0.6 \mathrm{cc}$ ). The Doppler fluximetric study of ovarian arteries revealed an absence of vascularization in the right ovary and a vascularization with a resistance index (RI) of 0.72 in the left ovary.

Six ovarian tissue slices were thawed, stitched together two-by-two with 4-0 Vicryl ${ }^{\circledR}$ (Ethicon Inc., NJ, USA), and then rapidly transferred to the operating room in $4^{\circ} \mathrm{C}$ phosphate-buffered saline (PBS) medium supplemented with $10 \%$ human serum. The ovarian surface was decorticated, two cortical strips were sutured to the right and two to the left ovary and the same sutures were used to close each ovary (Figure $1 \mathrm{D} \& \mathrm{E}$ ). The last two slices were inserted into a pocket created in a suprapubic area above the fascia (Figure $1 \mathrm{~F}$ ).

The following month she had spotting and the hormonal values were FSH $87 \mathrm{mIU} / \mathrm{ml}, \mathrm{LH} 60 \mathrm{mIU} / \mathrm{ml}$ and $\mathrm{E}_{2}$ $59 \mathrm{pg} / \mathrm{ml}$. The right ovary appeared homogeneous (volume $2 \mathrm{cc}$ ) with RI 0.84 , while the left ovary had two antral follicles of $5 \mathrm{~mm}$ (volume $2.2 \mathrm{cc}$ ) with RI 0.77. A $10 \times 2 \mathrm{~mm}$ fragment was visible at the heterotopic site. In August 2017 she had the first menstrual cycle, and FSH was $10 \mathrm{mIU} / \mathrm{ml}$, LH $6 \mathrm{mIU} / \mathrm{ml}$ and $\mathrm{E}_{2} 176 \mathrm{pg} / \mathrm{ml}$ on the third day of the cycle. The ultrasound showed four antral follicles (the largest of $10 \mathrm{~mm}$ ), the presence of a corpus luteum (volume $2 \mathrm{cc}$ ) and RI 0.5 in the right ovary; six antral follicles of five mm (volume $2.2 \mathrm{cc}$ ) and RI 0.5 in the left ovary. A $13 \times 6 \mathrm{~mm}$ fragment was visible at the heterotopic site. In the following 2 months, the menstrual cycle appeared regular and in November 2017, following a delay in the menstrual cycle, she performed a $\beta$ HCG test that was positive $(15039 \mathrm{mIU} / \mathrm{ml})$ and transvaginal ultrasound confirmed a viable intra-uterine pregnancy with fetal heartbeat. Pregnancy proceeded routinely with normal ultrasound scans at 12, 20 and 28 weeks gestation. After a normal uneventful pregnancy, a natural delivery at 39 weeks' gestational age was performed, and a healthy male baby weighing $3280 \mathrm{~g}$ and $51 \mathrm{~cm}$ long was born.

\section{Discussion}

The spontaneous birth reported here is the first in Italy to occur after ovarian tissue cryopreservation and transplantation in a patient suffering from an hematological disease (non-Hodgkin's lymphoma). In our country, only 
one birth was previously reported, by Revelli et al. [5], in a patient with a severe hematologic disease ( $\beta$-thalassemia) with POF after chemotherapy and bone marrow transplantation.

Non-Hodgkin's lymphoma is among the most frequent indications for ovarian tissue cryopreservation, because they represent a common tumor in young adult [6]. Since the ovarian tissue is harvested prior to anticancer treatments, it might contain malignant cells that could be reintroduced by cryopreserved ovarian tissue replanting, loading to a recurrence of primary disease in the healed patient. The risk of cryopreserved ovarian tissue contamination is estimated to be moderate (0.2-11\%) for non-Hodgkin's lymphoma patients [7]. Although several authors did not observe ovarian contamination by histological examination $[8,9]$, malignant cells were identified after histological and immunohistochemical examination in two patients [7]. Before transplantation, a careful evaluation of likely ovarian tissue infiltration by malignant cells is essential for clinical application. To date no standardized strategies are available to search neoplastic cells in the cryopreserved ovarian tissue. However, to increase the safety of ovarian tissue transplantation, the use of advanced and highly sensitive molecular approaches may dramatically improve the detection of malignant cells in the ovarian tissue. In our study, the molecular analysis was performed in order to determine rearrangement of genes coding for IGH (FR1-FR2-FR3 regions) and light chains (IGK), since no patient-specific markers were available.

The thawed ovarian tissue of our young woman, showing well-preserved follicles and stroma and good follicular reserve (eight follicles for $\mathrm{mm}^{2}$ ), was kept stored respectively for 4 and 5 years before transplantation. The first menstrual cycle was detected 2 months after the second transplantation and a viable pregnancy was achieved 3 months later.

As suggested by Dunlop et al. in 2016 [10], the pregnancy in our patient likely occurred from a follicle within the grafted tissue, given the clinically and biochemically diagnosed POF prior to the re-implantation, and the subsequent presence of a dominant follicle at the site of re-implantation with a corresponding corpus luteum formation following ovulation.

The recovery of ovarian function takes on average 4-5 months and is closely related to the folliculogenesis process. According to Gougeon et al. [11], in this period the oocyte and surrounding somatic cells undergo a series of changes that eventually lead to the development of a large antral follicle, capable of producing a mature oocyte. In our patient, the appearance of the first antral follicles in the grafted tissue and the $\mathrm{E}_{2}$ increase two months after the second transplantation are not consistent with the time course mentioned above. The rapid recovery of ovarian function is difficult to explain with the activation of follicles present in the ovarian tissue of the second graft. It is rather likely that the second transplantation, with the new ovarian tissue grafted and the mechanical surgical stimulus, has given a decisive 'activation' of the follicles present in the first transplanted ovarian tissue.

\section{Conclusion}

Ovarian tissue cryopreservation, thawing and transplantation have successfully restored ovarian function and fertility after tissue storage. This confirms that our technique of ovarian cortex freezing/thawing and storage effectively preserves the tissue viability and follicles integrity. Based on the outcomes obtained after ovarian tissue transplantation, we would like to suggest that this procedure not be considered experimental and we firmly believe that ovarian tissue cryopreservation should be offered to children and young women at high risk of POF due to sterilizing high dose chemotherapy.

\section{Financial \& competing interests disclosure}

The authors have no relevant affiliations or financial involvement with any organization or entity with a financial interest in or financial conflict with the subject matter or materials discussed in the manuscript. This includes employment, consultancies, honoraria, stock ownership or options, expert testimony, grants or patents received or pending, or royalties.

No writing assistance was utilized in the production of this manuscript.

\section{Ethical conduct}

This work has been approved by the Ethics Committee of S Orsola-Malpighi Hospital of Bologna, and informed consent for publication was obtained from the patient.

The authors state that they have obtained verbal and written informed consent from the patient/patients for the inclusion of their medical and treatment history within this case report, a copy of which was available for review by the editor of this journal. 


\section{Open access}

This work is licensed under the Attribution-NonCommercial-NoDerivatives 4.0 Unported License. To view a copy of this license, visit http://creativecommons.org/licenses/by-nc-nd/4.0/

\section{References}

Papers of special note have been highlighted as: $\bullet$ of interest; $\bullet \bullet$ of considerable interest

1. Donnez J, Dolmans MM. Fertility preservation in women. N. Engl. J. Med. 377(17), 1657-1665 (2017).

-. Describes the indications and results of fertility preservation techniques.

2. Canada AL, Schover LR. The psychosocial impact of interrupted childbearing in long-term female cancer survivors. Psychooncology 21(2), 134-143 (2012).

3. Fabbri R, Pasquinelli G, Keane D, Magnani V, Paradisi R, Venturoli S. Optimization of protocols for human ovarian tissue cryopreservation with sucrose, 1,2-propanediol and human serum. Reprod. Biomed. Online 21(6), 819-828 (2010).

- Presents the optimization of the human ovarian tissue cryopreservation protocol, testing different concentrations of human serum and cryoprotectants (propanediol and sucrose) in the freezing and thawing solutions.

4. Van Dongen JJ, Langerak AW, Brüggemann M et al. Design and standardization of PCR primers and protocols for detection of clonal immunoglobulin and T-cell receptor gene recombinations in suspect lymphoproliferations: report of the BIOMED-2 concerted action BMH4-CT98-3936. Leukemia 17(12), 2257-2317 (2003).

- Reports the molecular analysis performed in order to determine rearrangement of genes coding for immunoglobulins heavy (IGH; FR1-FR2-FR3 regions) and light chains (IGK) according to EUROCLONALITY protocols.

5. Revelli A, Marchino G, Dolfin E et al. Live birth after orthotopic grafting of autologous cryopreserved ovarian tissue and spontaneous conception in Italy. Fertil. Steril. 99(1), 227-230 (2013).

-• Describes a live birth obtained in Italy after autologous orthotopic transplantation of cryopreserved ovarian cortical tissue in a patient affected by $\beta$-thalassemia (intermedia phenotype) who underwent chemotherapy and bone marrow transplantation.

6. Iavarone I, Buzzoni C, Stoppa G, Steliarova-Foucher E. SENTIERI-AIRTUM Working Group. Cancer incidence in children and young adults living in industrially contaminated sites: from the Italian experience to the development of an international surveillance system. Epidemiol. Prev. 42(5S1-6S1), 76-85 (2018).

7. Dolmans MM, Luyckx V, Donnez J, Andersen CY, Greve T. Risk of transferring malignant cells with transplanted frozen-thawed ovarian tissue. Fertil. Steril. 99(6), 1514-1522 (2013).

-. Evaluates the presence of malignant cells in cryopreserved human ovarian tissue. Based on the available data, the risk of ovarian tissue contamination has been estimated for the different cancer diseases.

8. Meirow D, Hardan I, Dor J et al. Searching for evidence of disease and malignant cell contamination in ovarian tissue stored from hematologic cancer patients. Hum. Reprod. 23(5), 1007-1013 (2008).

- Describes the risk of transplanting malignant cells in a cohort of young women suffering from hematological malignancies who were submitted to store ovarian tissue in order to preserve fertility.

9. Kim SS, Radford J, Harris $\mathrm{M}$ et al. Ovarian tissue harvested from lymphoma patients to preserve fertility may be safe for autotransplantation. Hum. Reprod. 16(10), 2056-2060 (2001).

- Describes the risk of transplanting malignant cells in cohort of young women suffering from lymphomas who were submitted to store ovarian tissue in order to preserve fertility.

10. Dunlop CE, Brady BM, McLaughlin M et al. Re-implantation of cryopreserved ovarian cortex resulting in restoration of ovarian function, natural conception and successful pregnancy after haematopoietic stem cell transplantation for Wilms tumor. J. Assist. Reprod. Genet. 33(12), 1615-1620 (2016).

11. Gougeon A. Regulation of ovarian follicular development in primates: facts and hypotheses. Endocr. Rev. 17(2), 121-155 (1996). 
